\title{
Area-restricted search in Magellanic Woodpeckers: importance of tree senescence, forest composition and open habitats
}

Pablo Vergara ( $\nabla$ pablo.vergara@usach.cl)

Universidad de Santiago de Chile https://orcid.org/0000-0002-0024-1678

Francisca Maron-Perez

Universidad de Chile Facultad de Ciencias

Diego Caro

Universidad del Desarrollo

Gerardo E Soto

Cornell University

Javier A Simonetti

Universidad de Chile Facultad de Ciencias

Research

Keywords: foraging habitat quality, First-Passage Time, tree senescence, open habitats

Posted Date: November 17th, 2020

DOI: https://doi.org/10.21203/rs.3.rs-105140/v1

License: (9) This work is licensed under a Creative Commons Attribution 4.0 International License. Read Full License

Version of Record: A version of this preprint was published at Journal of Ornithology on March 25th, 2021. See the published version at https://doi.org/10.1007/s10336-021-01878-w. 


\section{Abstract \\ Background}

Large woodpecker species with stable territories, specialized diets and narrow habitat choices, such as the Magellanic Woodpecker (Campephilus magellanicus), are expected to adjust their movements based on the distribution of available resources within territories. Thus, Magellanic Woodpeckers should concentrate foraging activity in areas of higher quality, a behavior consistent with the area-restricted search (ARS) behavior. Although previous studies have deepened the understanding of how Magellanic woodpeckers select habitats, the assessment of ARS behavior would contribute to the identification of feeding areas important for their conservation and habitats hindering their movement.

\section{Methods}

We addressed the independent effects of tree senescence, forest succession, stand composition and open habitats on the adoption of area-restricted search (ARS) behavior in Magellanic Woodpeckers in a heterogeneous landscape dominated by southern beech forest in southern South America. Using GPS relocations from 24 woodpeckers, we estimated the First-Passage Time (FPT), a measure of the time individuals remain in a given area, with longer FPT values indicating the adoption of an ARS behavior. We determined the effects of habitat variables on FPT using a methodological framework based on Linear Mixed Effect models and a randomization procedure intended to reduce spatial autocorrelation arising from consecutive circles whose areas tend to be overlapped along trajectories.

\section{Results}

Averaged model coefficients showed that woodpeckers spent less time in sites dominated by the Antarctic beech (Nothofagus antarctica) and partially covered by open habitats. Conversely, FPT increased in stands and home ranges where tree senescence was higher.

\section{Conclusions}

The adoption of the ARS behavior in Magellanic Woodpecker is explained by forest composition, avoidance of open habitats and tree senescence. Our results suggest the conservation of Magellanic Woodpeckers in heterogeneous landscapes involve retention of senescent trees and restoring open areas in order to reduce edge habitat.

\section{Background}

Animals with stable territories, specialized diets and narrow habitat choices, such as some woodpecker species, are known to adjust their space use and movements based on the spatio-temporal heterogeneity 
of habitat resources [1,2]. Those animal species concentrate their movements in the habitats of higher foraging quality $[3,4],[5,6,7]$, a behavior known as area-restricted search (ARS) that, in many cases, involves the use of spatial memory to return to suitable sites within territories $[8,9]$. Determining the areas where animals concentrate their movements and foraging activity not only contributes to understand decision-making behavior or foraging efficiency but also to the identification of feeding areas important for the conservation of vulnerable species $[10,11,12,13]$. The assessment of ARS behavior has been, for instance, carried out in marine species, including sharks [14], seals [15], whales [16], dolphins [17], sea turtles [18], puffins [19], boobies [20] and albatross [21]. Although the ARS behavior has been tested in terrestrial species like carnivores [22], [13], small mammals [23], marsupials [24], lizards [25] and spiders [26], less attention has been paid to study it in woodpeckers. Determining habitat conditions under which forest specialized woodpeckers adopt an ARS behavior may contribute to sustainable landscape planning and forest management intended to increase habitat quality and connectivity.

The assessment of finer-scale movement patterns within territories provides a mechanistic basis for understanding the foraging decisions, which is especially evident in specialized animals [8]. In this sense, Hidden Markov Models (HMM) and State-space Models (SSM) have been used to distinguish between discrete modes of movement in woodpecker territories [27, 28], where each behavioral mode is interpreted to represent a distinct behavior (e.g., foraging vs. traveling). Those discrete-time modelling approaches assume that, while moving across its home range, a woodpecker can either remain in a same mode or switch to a different mode between two successive time intervals [29]. Foraging woodpeckers, however, may stay for relatively long periods in the foraging mode when using forest stands or forest sites of high quality, as found in animals adopting an area-restricted search (ARS) strategy [30, 31]. Although HMM and SSM capture the fine-grained step-by-step movement patterns, these approaches are usually difficult to implement and do not provide spatially explicit inference about the habitat area that animals use when moving. Alternative methodological approaches, such as First-Passage Time (FPT, [31] and residence time [32], provide statistical frameworks for the quantification of habitat areas where animals remain for more times, thus allowing for testing associations between ARS behavior and habitat conditions [33]. Indeed, FPT and residence time are useful approaches to evaluate habitat preferences and movement ecology of species that occupy spatially heterogeneous habitats $[34,35,36]$.

In this study, we address the movement strategies adopted by Magellanic Woodpeckers (Campephilus magellanicus) in a heterogeneous forested landscape. Field observations suggest that Magellanic Woodpeckers move between neighboring trees by selecting and adjusting residence times in each visited tree based on its attributes, spending more time at trees that are highly decayed [37]. The tree decay-stage serves as a cue of habitat quality for woodpeckers, offering them with information about the presence of their prey inside trees, such as the larvae of long-horned beetles (Microplophorus magellanicus) [3, 37, 38, 28, 39]. Although movement decisions of Magellanic Woodpeckers have been shown to depend on the availability of senescent and dead trees [37,28], to date, no studies have determined how the ARS behavior of woodpeckers varies across an heterogenous landscape. Depending on forest disturbances, territories of Magellanic Woodpeckers may include forest stands that vary in tree species composition and age (old-growth vs. second-growth), but also include open habitats like prairies, bushlands, exotic 
beaver ponds, and bogs $[40,41,39]$. Woodpeckers may respond to such habitat heterogeneity by modifying their movement patterns when finding open habitats or intensifying their searching for prey in forest stands with more senescent trees. Here, we aim at examining the adoption of an ARS strategy across a heterogeneous forested landscape using the FPT approach, which allows for the identification of areas where woodpeckers behave as ARS foragers. We hypothesized that woodpeckers remain longer (i.e., higher FPT) in areas where individual trees are more senescent but also in areas dominated by oldgrowth forest with low representation of open habitats.

\section{Methods}

We conducted our study in a forest landscape located on Navarino Island in the southernmost region of Chile (Fig. 1). The study landscape was covered by southern beech forest of Nothofagus betuloides, $N$. pumilio, and N. antartica (Fig. 1). Open habitats also were present in this landscape and included patches of shrublands, wetlands, peat bogs, meadows, and ponds, with the latter two being produced by the introduced beaver (Castor canadensis) (Fig. 1; [41]). The cover of N. pumilio, N. betuloides, and $N$. antarctica was $29.2 \%, 29.5 \%$ and $6.4 \%$, respectively (Table 1 ). Although forest stands in old-growth stage of succession covered $45.3 \%$ of the land, forest disturbances (e.g., logging and fires) have resulted in some second-growth stands (20.2\%). Shrublands and meadows (upland open areas) covered $10.2 \%$ of the study area and peat bogs and pond (lowland open areas) represented $6.5 \%$ of the landscape (Table 1).

Table 1

Cover (\%) of each habitat type in the study area where the movement of Magellanic Woodpecker was studied. For PSRI, the mean and SE value are shown.

\begin{tabular}{|ll|}
\hline Habitat type & Total cover (\%) \\
\hline N. antarctica & 6.38 \\
\hline N. betuloides & 29.23 \\
\hline N. pumilio & 29.52 \\
\hline Open upland habitats & 10.21 \\
\hline Open lowland habitats & 6.49 \\
\hline PSRI* & $-0.73(0.31)$ \\
\hline Old-growth forest & 45.34 \\
\hline Second-growth forest & 20.22 \\
\hline *mean (SD) & \\
\hline
\end{tabular}

Movement data 
We acquired GPS locations from 24 tagged male Magellanic Woodpeckers [39, 28] using ATS G10 UltraLITE GPS Logger (Advanced Telemetry Systems, Inc.) devices, each attached to a very highfrequency transmitter (ATS model A2440, $2.3 \mathrm{~g}$ ) for later recovery. GPS devices were placed on the back of adult male woodpeckers using a small amount of epoxy to six feathers. We chose adult males because males guide family groups by eliciting a dominant social behavior while moving across forest habitat $[42,43]$. The locations of woodpeckers were recorded every 5 min between 08:00 to $16: 00$ and during the 2014-2015 post-reproductive period (Jan to Mar).

We estimated the accuracy (measurement error) of GPS locations as $12.9 \pm 2.9 \mathrm{~m}$ (mean \pm SE), which was obtained by quantifying the Euclidean distances $(\mathrm{m})$ between 12 different GPS measurements and the actual position of a reference point identified on an imagery-based map layer [28]. We calculated the overall speed for each woodpecker by dividing the total traveled distance (i.e. the sum of the distance between GPS relocations) by the total time of a given burst of continuous relocations.

\section{First-passage time}

We examined the role of habitat heterogeneity on the movement of woodpeckers by estimating the firstpassage time (FPT) from GPS location data. FPT can be used as an indicator of foraging behavior along animal's tracks, with longer FPT areas being interpreted as evidence of ARS at ecologically proper spatial scales $[31,44,45]$. The first-passage time is defined as the time spent by an individual in circles of radius $r$ centered on subsequent GPS positions along each trajectory (i.e., a movement path consisting of a sequence of GPS locations within the home range; Fig. 2A;[46]). As $r$ increases, longer trajectory sections will be included in the circle [31]. We established the proper spatial scale of FPT analysis by searching the value of $r$ that maximizes the relative variance $[S(r)]$ of the FPT because the ability of the FPT to detect area restricted search (ARS) increases as the variance takes maximum values [31]. The ARS is a behavior characterized by slow and tortuous movements typically displayed by woodpeckers when selecting trees for foraging [2].

To estimate the FPT, we used the fpt function of the R package adehabitatLT. The last six woodpecker's data were excluded from further analysis because it was not possible to define a regular trajectory due to the different time lag between relocations (Fig. S1). The first-passage time method is designed for trajectories with three or more relocations, so the trajectory data with less than three observations were eliminated. Because observations of six woodpeckers were discarded from the analysis, we estimated the first-passage time (FPT) from the trajectories of 18 woodpeckers. We maximized $S(r)$ for each trajectory and individual by estimating FPT over 50 different radii $(r)$ in a range from 12 to $250 \mathrm{~m}$ corresponding, respectively, to the GPS accuracy and a quarter of the calculated net distance displacement of Magellanic Woodpeckers [32]. We determined the proper FPT scale, $r$ value at which $S(r)$ reached its maximum value, by examining plots of $S(r)$ against $r$. From $S(r)$ plot examination, a set of 36 trajectories were selected out of 62 trajectories (Fig. S2). When we did not observe a maximum value of $S(r)$, we assumed that the path traced by a woodpecker was random and did not represent a movement pattern including different behavioral modes, as shown by the eighth trajectory of woodpecker 3 (Fig. S2). 
However, we considered proper FPT scales for trajectories where a local maximum was observed, for example, the first trajectory of woodpecker 4 (Fig. S2). Based on the proper FPT scales, we defined two spatial scales to quantify properties of the habitat used by woodpeckers (see below), including site (habitat-patch) scale, defined by the area of each FPT circle (Fig. 2A), and home-range scale, defined by the area comprising the union of all the FPT circles along the trajectory (Fig. 2B).

Habitat variables

We quantified habitat variables at the site and home-range scales using a high-resolution $(0.50 \mathrm{~m})$ multispectral image from the WorldView-2 sensor (2014). We created geographic information system (GIS) layers of the main categories of habitat types and tree species in the study site as well as a remote sensing index of tree senescence (Table 1). We used digital supervised classification and a Bayesian maximum likelihood algorithm carried out by [39] to classify habitat types based on age and composition of forest stands as well as the cover of different habitat types. We categorized habitats as old-growth forest, second-growth forest, open upland (shrub and meadows), and open lowland (peatlands and beaver ponds). We also determined the composition of dominant tree species by quantifying the cover of N. Antarctica, N. betuloides, and N. pumilio. Tree senescence was estimated with the remote sensingbased Plant Senescence Reflectance Index (PSRI), which distinguishes between tree decay states based on the spectral carotenoid/chlorophyll ratio with increasing values for increasing tree decay [39]. We used an image segmentation algorithm to identify individual trees, estimate their PSRI and classify them by species of tree [37, 39]. The PSRI values of the subpolar forest range from -2.7 to 0.4 (Table 1, [39]).

We used the GIS maps of habitat type, tree composition and PSRI to derive the habitat variables used in statistical analysis. First, for each FPT circle, we estimated the percentage of old-growth forest, secondgrowth forest, open upland habitats and open lowland habitats. Second, we estimated the percentage cover of the dominant Nothofagus species. Third, we averaged PSRI values over all cells in each FPT circle and considered those values as estimates of tree senescence at the site level (Fig. 2). Fourth, PSRI values were averaged over all FPT circles, considering those values as estimates of tree senescence at the home-range level (Fig. 2). Tree senescence estimated at the site and home-range scales were not collinear (see below; Table S1), hence those variables were included in the same statistical models. All tree species located at the site and home-range levels (i.e. all trees across the trajectories) were interpreted as the foraging habitat quality at the home-range scale [37].

Statistical modelling

We used a methodological framework based on Linear Mixed Effect models (LMM) to determine the effects of habitat variables on FPT (Fig. 3). This approach was intended to reduce spatial autocorrelation arising from consecutive circles whose areas tend to be overlapped along trajectories ([31]; Fig. 3A). To analyze independent FPT data, we performed a randomization procedure by randomly selecting subsets of not-overlapping circles for each trajectory (Fig. 3). This procedure was repeated 1000 times, which resulted in 1000 sets of trajectories, each contained independent data later used in LME analyses (Fig. 3). LME were fitted to different datasets, which precluded comparing models with a criterion derived from 
likelihood functions, such as the Akaike Information Criteria (AIC; [47]). Thus, for each of the 1000 sampled datasets, we used the RMark R package to compute model-averaged coefficients based on the AIC weights [48]. The AICC weight quantifies the probability that a given model is the best among a set of candidate models $[48,49]$. The distributions of model-averaged coefficients were assumed to represent the effects of predictors. The mean and $95 \%$ confidence intervals of those distributions were used to interpret the significance of the coefficients. Model averaging was carried out on a set of 93 models including all possible combination of variables derived from a global model. The global model was built to assess the independent effects of habitat variables. Thus, we checked collinearity with the variance inflation factor (VIF; Table S1), where a VIF > 10 indicates lack of orthogonality between variables [50]. From this analysis, we detected that the percent cover of Nothofagus species and that of old-growth forest were collinear, so we discarded the latter from analyses (Table S1). Therefore, the global model included as predictors the cover percentage of dominant Nothofagus species, second-growth forest, open upland habitats and open lowland habitats, in addition to the PSRI values quantified at site and home range levels. The dependent variable (FPT) was divided by the area of each circle to obtain the time woodpeckers spent in an area of similar size $\left(\mathrm{s} / \mathrm{m}^{2}\right)$, and thus to allow the comparison between trajectories with circles of different radii. The trajectory and individual were included as random effects in LMM, with analysis being performed using the Ime4 R package [51].

\section{Results}

The overall speed and radius of FPT circles differed among individuals and trajectories, with speed ranging from 0.1 to $36.89 \mathrm{~m} / \mathrm{s}$ (mean $\pm \mathrm{SE}: 12.8 \pm 1.1 \mathrm{~m} / \mathrm{s}$; Table S2) and radius ranging from 21.7 to $225.7 \mathrm{~m}$ (98.3 $\pm 4.6 \mathrm{~m}$; Table S3). Significant effects of tree senescence (PSRI), tree composition, and open habitats on the FPT of woodpeckers were estimated from the $95 \%$ Confidence Intervals of the distributions of model-averaged coefficients (Table 2). Specifically, FPT was lower when woodpeckers moved in stands dominated by $N$. antarctica, open upland habitats, and open lowland habitats (Table 2; Fig. 4). Conversely, FPT was higher in stands and home ranges where tree senescence (PRSI) was higher at the site and home-range levels (Table 2; Fig. 4). 
Table 2

Summary statistics of the distributions of model-averaged coefficients associated with habitat variables affecting the First Passage-Time (FPT) of Magellanic Woodpecker. The mean, standard error (SE) and 95\% confidence intervals $(\mathrm{Cl})$ are shown. Significant effects (bolded) are interpreted from $\mathrm{Cl}$ values (see text).

\begin{tabular}{|lllll|}
\hline Variable & Mean & SE & Lower Cl & Upper CI \\
\hline PSRI (site level) & $\mathbf{0 . 1 0}$ & $\mathbf{0 . 0 0}$ & 0.01 & $\mathbf{0 . 2 1}$ \\
\hline PSRI (home-range level) & $\mathbf{0 . 6 1}$ & $\mathbf{0 . 0 2}$ & $\mathbf{0 . 0 0}$ & 1.62 \\
\hline N. antarctica (\%)* & -0.21 & $\mathbf{0 . 0 0}$ & -0.41 & -0.01 \\
\hline N. betuloides (\%)* & 0.01 & 0.00 & -0.22 & 0.33 \\
\hline N. pumilio (\%)* & 0.01 & 0.01 & -0.23 & 0.43 \\
\hline Open Upland habitats (\%)* & -0.37 & $\mathbf{0 . 0 1}$ & -0.94 & -0.14 \\
\hline Second-growth forest (\%)* & 0.05 & 0.01 & -0.42 & 0.71 \\
\hline Open Lowland habitats (\%)* & -0.27 & $\mathbf{0 . 0 0}$ & -0.54 & -0.10 \\
\hline *value $\times 100$ & & & & \\
\hline
\end{tabular}

\section{Discussion}

Our results suggest that adoption of an area-restricted search (ARS) strategy by Magellanic Woodpeckers is influenced by the quality of foraging habitat (i.e., tree senescence as estimated by PSRI) at different scales, in addition to the cover of open habitats and tree stand composition. Furthermore, the positive effect of tree decay at the home-range scale on FPT suggests that woodpeckers adjust their movements based on the foraging quality of home ranges. Our previous observations have revealed Magellanic Woodpeckers switch to the transient mode (exploratory movement) when the trees located in the proximity of the individual are either, on average, poor in quality or highly variable in quality [28]. Moreover, the residence time of Magellanic Woodpeckers on individual trees is positively associated with the home range foraging quality [37], suggesting that individuals with more suitable territories adopt a more intensive prey searching, consistent with an ARS behavior. Woodpecker preferences for more senescent trees, as found in Magellanic Woodpeckers, have also been reported in other species of woodpeckers [1]. For instance, Red-cockaded Woodpeckers (Leuconotopicus borealis) intensify foraging activity when surrounded by a habitat of better quality [27] whereas Black-backed Woodpeckers (Picoides arcticus) have smaller home ranges in higher-quality habitat (i.e., habitats with more recently killed trees; [52]). However, habitat preferences of woodpeckers also can be influenced by factors other than foraging habitat quality. For example, fledgling Northern Flickers (Colaptes auratus) occupied habitats with greater densities of trees, presumably for protection against predators [53]). Some large woodpeckers, such as Pileated Woodpeckers (Dryocopus pileatus), spend much of their time defending their roosting and 
nesting sites [54]. Thus, woodpeckers eventually may remain longer in sites offering them with habitat resources different than those used when foraging.

The cover of non-forest habitats was important in influencing woodpecker movements. Magellanic Woodpeckers spent less time in open habitats, suggesting that woodpeckers tended to adopt a transient movement when moving across, or near to, meadows, shrub, and peatlands. Our unpublished records at the study site suggest that woodpeckers flying through open areas are more susceptible to predation by raptors such as Southern Caracaras (Caracara plancus) and Chilean Hawk (Accipiter chilensis). Thus, woodpeckers could avoid crossing open habitats or spending long times in forest sites adjacent to open habitats, and this avoidance behavior possibly responds to increased predation risk in open areas.

Our results provide insights into woodpecker's preferences for Nothofagaceae tree species composing old-growth forest ecosystems, as shown by the negative effect of $N$. antarctica cover on the residence time of woodpeckers. Previous studies indicate the remote-sensed characterization of tree senescence in $N$. antarctica differs from that of the other Nothofagus species [39]. These findings may imply that woodpeckers foraging in an old-growth forest of $N$. antarctica face a distinctive, and possibly less abundant, assemblage of prey (i.e., saproxylic invertebrates) that is inherent to ecosystems with watersaturated soils like forest stands of $N$. antarctica. However, the response of Magellanic Woodpeckers to forests covered by $N$. antarctica requires further exploration.

\section{Conclusions}

The adoption of the ARS behavior in Magellanic Woodpecker is accounted for forest composition, avoidance of open habitats and tree senescence. This knowledge had the potential to help the conservation of Magellanic Woodpeckers in landscapes subject to high pressures from anthropogenic land-use change [55]. We recommended that conservation efforts should focus on protecting the remaining old-growth native forest, restoring open areas and reducing edge habitat, especially in protected areas surrounded by anthropogenic landscapes $[55,56]$. With these indicators, it might be possible to distinguish the more suitable habitats for woodpeckers to better guide the conservation efforts while using these management guidelines to conserve forest communities [57]. Taking actions to preserve the Magellanic Woodpeckers would also help to preserve other forest-dwelling species due to their ecological importance as primary cavity excavator of south Patagonian forest and even other possible important ecological roles. Our results also provided valuable insights into the implementation of sustainable management in the southernmost forests of the world. The existing national forest legislation considers traditional shelterwood cut as the harvesting system to be employed in the subpolar Nothofagus forest. However, shelterwood cutting is intended to retain the canopy cover rather than preserve deadwood, thus being of low value for saproxylic biota associated with these forest ecosystems. Therefore, our results pose the need to retain old-growth forest conditions at the spatial scales that are relevant for saproxylic species at the top of the food chain, as the case of Magellanic Woodpeckers.

\section{Declarations}




\section{Acknowledgements}

This study was funded by FONDECYT 1180978. We thank Data Science Institute (Universidad del Desarrollo, Chile) for support in processing data.

\section{References}

1. Nappi A, Drapeau P, Leduc A. How important is dead wood for woodpeckers foraging in eastern North American boreal forests? For Ecol Manage. 2015;346:10-21.

2. Vergara PM, Saura S, Pérez-Hernández CG, Soto GE. Hierarchical spatial decisions in fragmented landscapes: Modeling the foraging movements of woodpeckers. Ecol Modell. 2015;300.

3. Vergara P, Schlatter RP. Magellanic woodpecker (Campephilus magellanicus) abundance and foraging in Tierra del Fuego, Chile. J Ornithol. 2004;145.

4. Farris $\mathrm{KL}$, Huss MJ, Zack S. The role of foraging woodpeckers in the decomposition of ponderosa pine snags. Condor. 2004;106:50-9.

5. Saab VA, Russell RE, Dudley JG. Nest densities of cavity-nesting birds in relation to postfire salvage logging and time since wildfire. Condor. 2007;109:97-108.

6. Macey JN, Burt DB, Saenz D, Conner RN. Habitat use and avoidance by foraging red-cockaded woodpeckers in east Texas. Southeast Nat. 2016;15:76-89.

7. Matseur EA, III FRT, Dickerson BE, Rumble MA, Millspaugh JJ. Black-backed woodpecker abundance in the Black Hills. J Wildl Manage. 2018;82:1039-48.

8. Fagan WF, Lewis MA, Auger-Méthé M, Avgar T, Benhamou S, Breed G, et al. Spatial memory and animal movement. Ecol Lett. 2013;16:1316-29.

9. Fagan WF, Hoffman T, Dahiya D, Gurarie E, Cantrell RS, Cosner C. Improved foraging by switching between diffusion and advection: benefits from movement that depends on spatial context. Theor Ecol. 2019;1-10.

10. Robinson PW, Simmons SE, Crocker DE, Costa DP. Measurements of foraging success in a highly pelagic marine predator, the northern elephant seal. J Anim Ecol. 2010;79:1146-56.

11. Lascelles BG, Taylor PR, Miller MGR, Dias MP, Oppel S, Torres L, et al. Applying global criteria to tracking data to define important areas for marine conservation. Divers Distrib. 2016;22:422-31.

12. Carter MID, Bennett KA, Embling CB, Hosegood PJ, Russell DJF. Navigating uncertain waters: a critical review of inferring foraging behaviour from location and dive data in pinnipeds. Mov Ecol. 2016;4:25.

13. Ironside KE, Mattson DJ, Theimer T, Jansen B, Holton B, Arundel T, et al. Quantifying animal movement for caching foragers: the path identification index (PII) and cougars, Puma concolor. Mov Ecol. 2017;5:1-17.

14. Meese EN, Lowe CG. Active acoustic telemetry tracking and tri-axial accelerometers reveal fine-scale movement strategies of a non-obligate ram ventilator. Mov Ecol. 2020;8:8. 
15. Bras Y Le, Jouma'a J, Guinet C. Three-dimensional space use during the bottom phase of southern elephant seal dives. Mov Ecol. 2017;5:18.

16. Palacios DM, Bailey H, Becker EA, Bograd SJ, DeAngelis ML, Forney KA, et al. Ecological correlates of blue whale movement behavior and its predictability in the California Current Ecosystem during the summer-fall feeding season. Mov Ecol. 2019;7:26.

17. Bailey H, Lyubchich V, Wingfield J, Fandel A, Garrod A, Rice AN. Empirical evidence that large marine predator foraging behavior is consistent with area-restricted search theory. Ecology. 2019;100:e02743.

18. Freitas C, Caldeira R, Reis J, Dellinger T. Foraging behavior of juvenile loggerhead sea turtles in the open ocean: from Lévy exploration to area-restricted search. Mar Ecol Prog Ser. 2018;595:203-15.

19. Bennison A, Quinn JL, Debney A, Jessopp M. Tidal drift removes the need for area-restricted search in foraging Atlantic puffins. Biol Lett. 2019;15:20190208.

20. Sommerfeld J, Kato A, Ropert-Coudert Y, Garthe S, Hindell MA. Foraging parameters influencing the detection and interpretation of area-restricted search behaviour in marine predators: a case study with the masked booby. PLoS One. 2013;8:e63742.

21. Conners MG, Hazen EL, Costa DP, Shaffer SA. Shadowed by scale: subtle behavioral niche partitioning in two sympatric, tropical breeding albatross species. Mov Ecol. 2015;3:28.

22. Lode T. Functional response and area-restricted search in a predator: seasonal exploitation of anurans by the European polecat, Mustela putorius. Austral Ecol. 2000;25:223-31.

23. Borgne H Le, Fortin D. Functional responses in habitat use explain changes in animal-habitat interactions during forest succession. Can J For Res. 2020;50:549-56.

24. Orlando CG, Tews A, Banks P, McArthur C. The power of odour cues in shaping fine-scale search patterns of foraging mammalian herbivores. Biol Lett. 2020;16:20200329.

25. Eifler DA, Baipidi K, Eifler MA, Dittmer D, Nguluka L. Influence of prey encounter and prey identity on area-restricted searching in the lizard Pedioplanis namaquensis. J Ethol. 2012;30:197-200.

26. Patt JM, Pfannenstiel RS. Characterization of restricted area searching behavior following consumption of prey and non-prey food in a cursorial spider, Hibana futilis. Entomol Exp Appl. 2009;132:13-20.

27. McKellar AE, Langrock R, Walters JR, Kesler DC. Using mixed hidden Markov models to examine behavioral states in a cooperatively breeding bird. Behav Ecol. 2015;26:148-57.

28. Vergara PM, Soto GE, Rodewald AD, Quiroz M. Behavioral switching in Magellanic woodpeckers reveals perception of habitat quality at different spatial scales. Landsc Ecol. 2019;34:79-92.

29. Jonsen ID, Flemming JM, Myers RA. Robust state-space modeling of animal movement data. Ecology. 2005;86:2874-80.

30. Kareiva P, Odell G. Swarms of predators exhibit" preytaxis" if individual predators use area-restricted search. Am Nat. 1987;130:233-70. 
31. Fauchald P, Tveraa T. Using first-passage time in the analysis of area-restricted search and habitat selection. Ecology. 2003;84:282-8.

32. Barraquand F, Benhamou S. Animal movements in heterogeneous landscapes: identifying profitable places and homogeneous movement bouts. Ecology. 2008;89:3336-48.

33. Freitas $C$, Kovacs KM, Lydersen $C$, Ims RA. A novel method for quantifying habitat selection and predicting habitat use. J Appl Ecol. 2008;45:1213-20.

34. Byrne ME, Chamberlain MJ. Using first-passage time to link behaviour and habitat in foraging paths of a terrestrial predator, the racoon. Anim Behav. 2012;84:593-601.

35. Corre M Le, Dussault C, Côté SD. Detecting changes in the annual movements of terrestrial migratory species: using the first-passage time to document the spring migration of caribou. Mov Ecol. 2014;2:1-11.

36. Zhang Z, Sheppard JK, Swaisgood RR, Wang G, Nie Y, Wei WEI, et al. Ecological scale and seasonal heterogeneity in the spatial behaviors of giant pandas. Integr Zool. 2014;9:46-60.

37. Vergara PM, Soto GE, Moreira-Arce D, Rodewald AD, Meneses LO, Perez-Hernandez CG. Foraging behaviour in magellanic woodpeckers is consistent with a multi-scale assessment of tree quality. PLoS One. 2016;11:e0159096.

38. Vergara PM, Meneses LO, Grez AA, Quiroz MS, Soto GE, Pérez-Hernández CG, et al. Occupancy pattern of a long-horned beetle in a variegated forest landscape: linkages between tree quality and forest cover across spatial scales. Landsc Ecol. 2017;32:279-93.

39. Soto GE, Pérez-Hernández CG, Hahn IJ, Rodewald AD, Vergara PM. Tree senescence as a direct measure of habitat quality: Linking red-edge Vegetation Indices to space use by Magellanic woodpeckers. Remote Sens Environ. 2017;193:1-10.

40. Ojeda V, Chazarreta L. Home range and habitat use by Magellanic Woodpeckers in an old-growth forest of Patagonia. Can J For Res. 2014;44:1265-73.

41. Soto GE, Vergara PM, Lizama ME, Celis C, Rozzi R, Duron Q, et al. Do beavers improve the habitat quality for Magellanic Woodpeckers? Bosque. 2012;33:271-4.

42. Duron Q, Jiménez JE, Vergara PM, Soto GE, Lizama M, Rozzi R. Intersexual segregation in foraging microhabitat use by Magellanic Woodpeckers (Campephilus magellanicus): Seasonal and habitat effects at the world's southernmost forests. Austral Ecol. 2018;43:25-34.

43. Ojeda VS. Breeding biology and social behaviour of Magellanic Woodpeckers (Campephilus magellanicus) in Argentine Patagonia. Eur J Wildl Res. 2004;50:18-24.

44. Fauchald P, Tveraa T. Hierarchical patch dynamics and animal movement pattern. Oecologia. 2006;149:383-95.

45. Kappes MA, Shaffer SA, Tremblay Y, Foley DG, Palacios DM, Robinson PW, et al. Hawaiian albatrosses track interannual variability of marine habitats in the North Pacific. Prog Oceanogr. 2010;86:246-60. 
46. Frair JL, Merrill EH, Visscher DR, Fortin D, Beyer HL, Morales JM. Scales of movement by elk (Cervus elaphus) in response to heterogeneity in forage resources and predation risk. Landsc Ecol. 2005;20:273-87.

47. Korner-Nievergelt F, Roth T, Felten S Von, Guélat J, Almasi B, Korner-Nievergelt P. Bayesian data analysis in ecology using linear models with R, BUGS, and Stan. Academic Press; 2015.

48. Burnham KP, Anderson DR. A practical information-theoretic approach. Model Sel multimodel inference, 2nd edSpringer, New York. 2002;2.

49. Grueber CE, Nakagawa S, Laws RJ, Jamieson IG. Multimodel inference in ecology and evolution: challenges and solutions. J Evol Biol. 2011;24:699-711.

50. Craney TA, Surles JG. Model-dependent variance inflation factor cutoff values. Qual Eng. 2002;14:391-403.

51. Bates D, Mächler M, Bolker B, Walker S. Fitting linear mixed-effects models using Ime4. arXiv Prepr arXiv14065823. 2014;

52. Tingley MW, Wilkerson RL, Bond ML, Howell CA, Siegel RB. Variation in home-range size of Blackbacked Woodpeckers. Condor Ornithol Appl. 2014;116:325-40.

53. Gow EA, Wiebe KL. Survival and habitat use by fledgling northern flickers in a fragmented forest landscape. J Wildl Manage. 2014;78:273-81.

54. Tomasevic JA, Marzluff JM. Space use of suburban Pileated Woodpeckers (Dryocopus pileatus): Insights on the relationship between home range, core areas, and territory. Oecologia. 2018;187:1523.

55. Vergara P, Meneses L, Saavedra M, Diaz F, Norambuena K, Fierro A, et al. Magellanic Woodpeckers in three national parks of central-southern Chile: habitat effects and population variation over the last two decades. Avian Conserv Ecol. 2017;12.

56. Menezes R, Pimentel GM, Rosa RS, Ribeiro AL. Recurrent seasonal occurrence of the Lineated Woodpecker (Dryocopus lineatus) in a riparian fragment of the Atlantic Forest, northeastern Brazil. Ornithol Res. 2019;27:27-30.

57. Home R, Keller C, Nagel P, Bauer N, Hunziker M. Selection criteria for flagship species by conservation organizations. Environ Conserv. 2009;139-48.

\section{Figures}




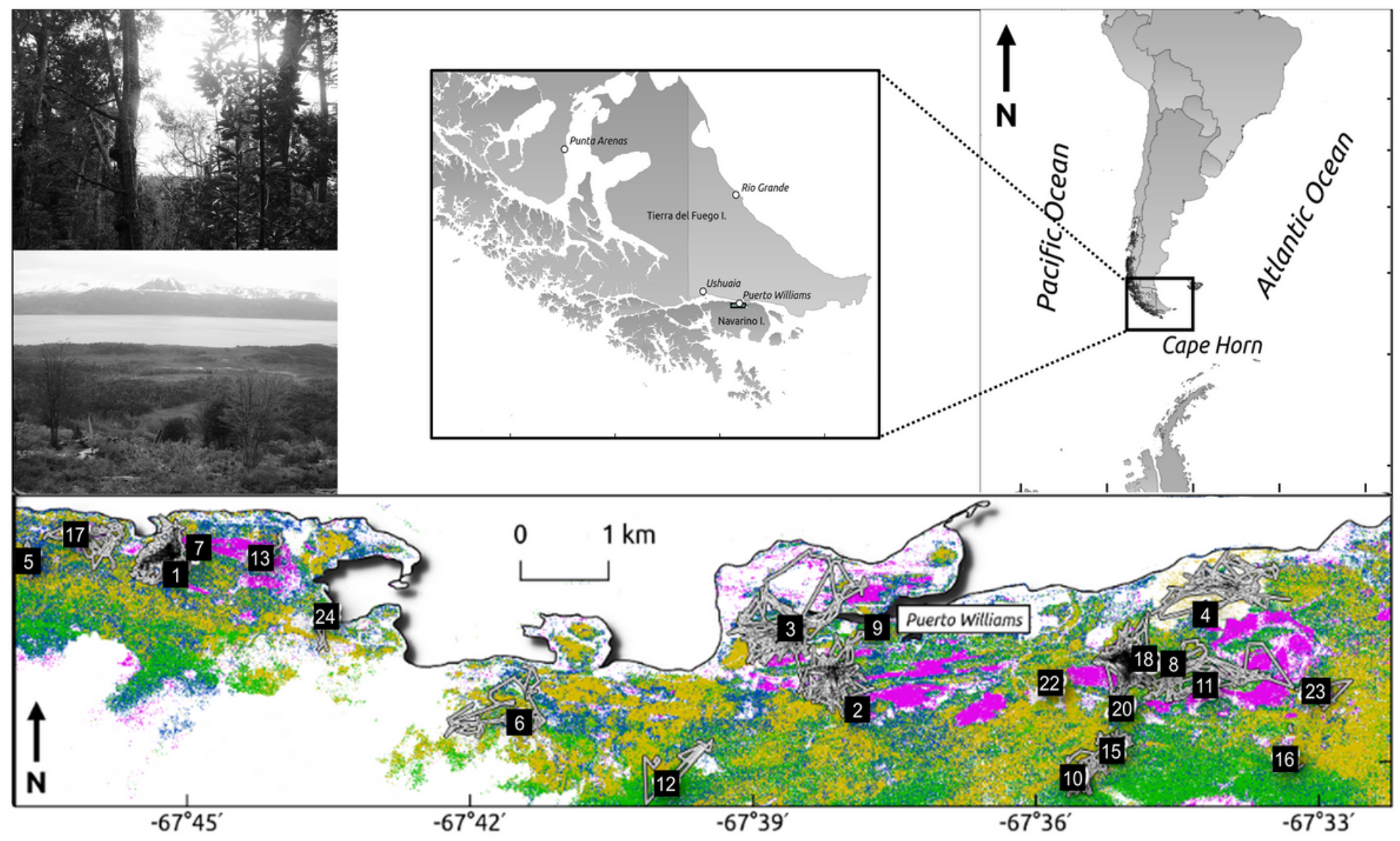

Figure 1

Map of the study site, showing vegetation composition. The color scale denotes changes in dominant tree species (Nothofagus pumilio, Nothofagus betuloides and Nothofagus antarctica) and non-forest areas. The numbers on the bottom map represent the movement trajectories of GPS-tracked Magellanic Woodpecker individuals includede in this study. Photos show details of the forest habitat (below) and open habitat (above). 


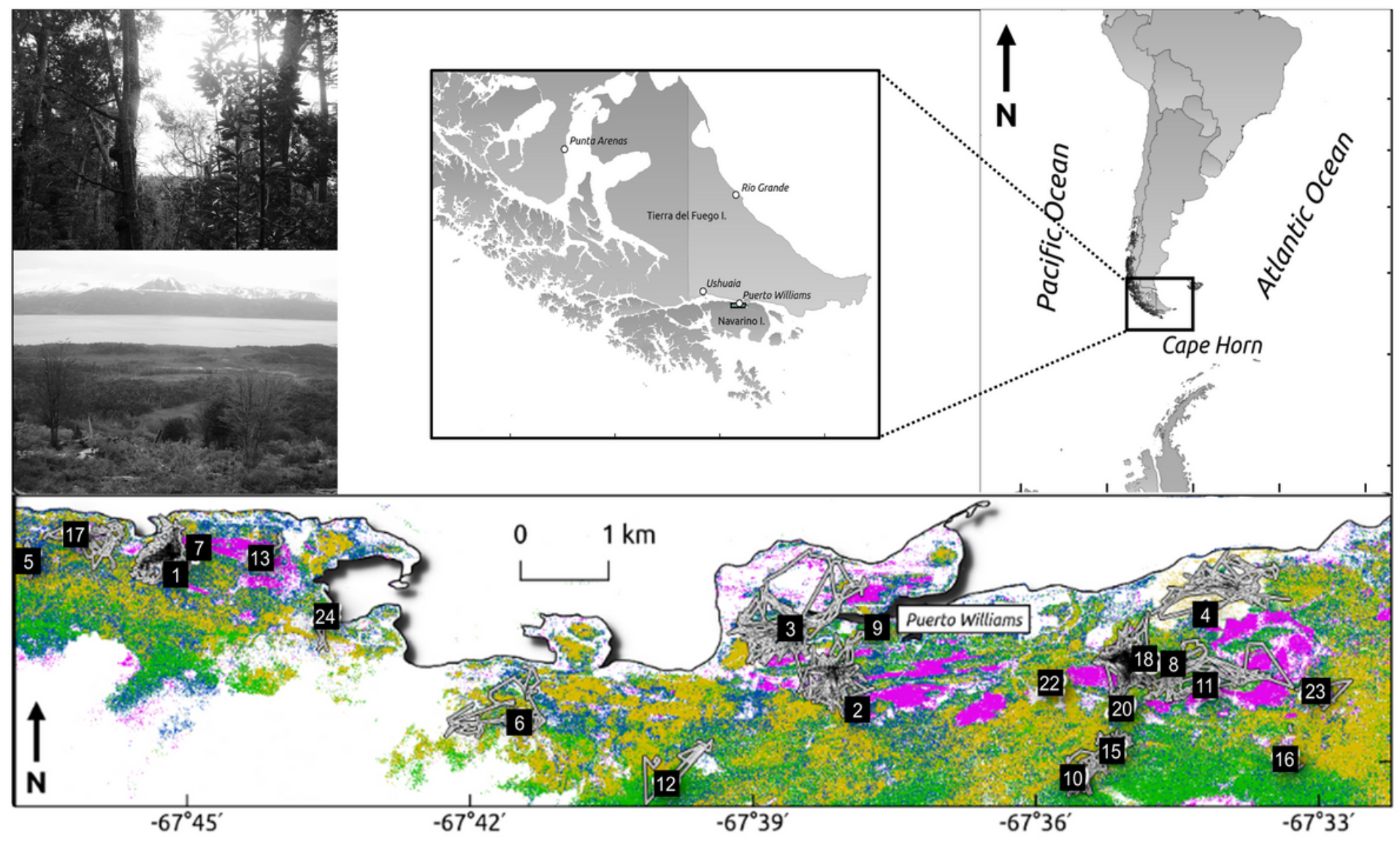

Figure 1

Map of the study site, showing vegetation composition. The color scale denotes changes in dominant tree species (Nothofagus pumilio, Nothofagus betuloides and Nothofagus antarctica) and non-forest areas. The numbers on the bottom map represent the movement trajectories of GPS-tracked Magellanic Woodpecker individuals includede in this study. Photos show details of the forest habitat (below) and open habitat (above).

A

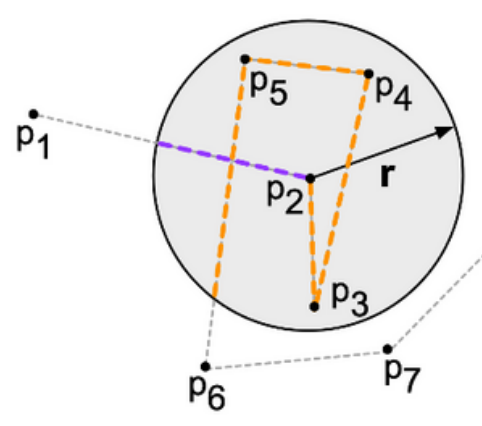

B

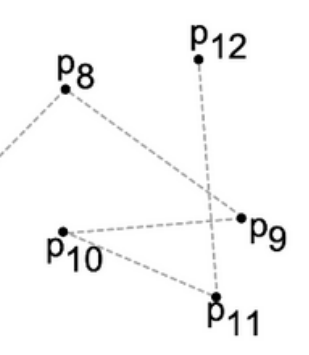

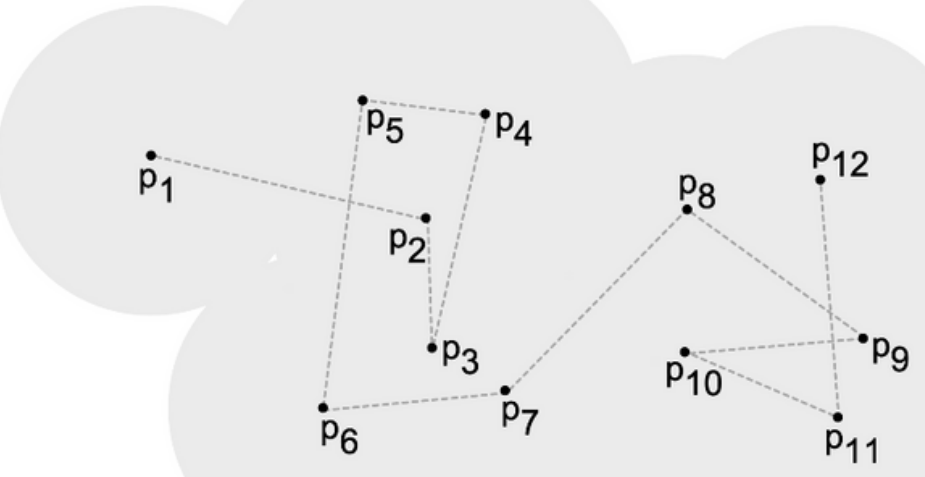


Schematic representation of First-Passage Time (FPT) measurement of Magellanic Woodpeckers moving at the site level (A) and home range level (B), as based on a trajectory with 12 relocations (pi). In $A$, the segment of the trajectory (in purple) represents the FPTB1 and in orange the FPTF2 of the circle with radius $r$ with center at $\mathrm{p} 2$.

A

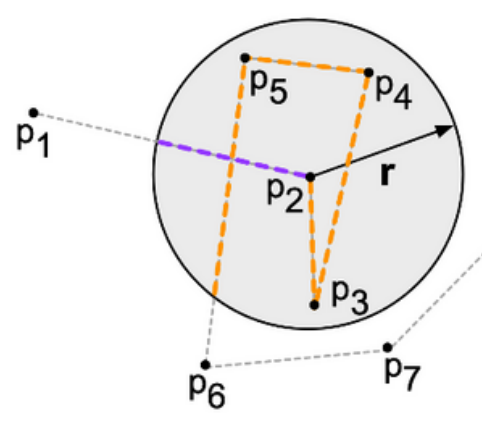

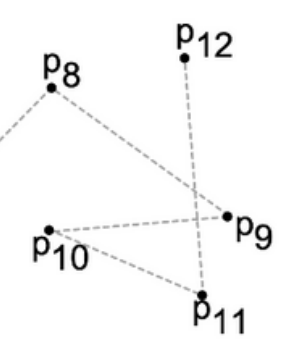

B

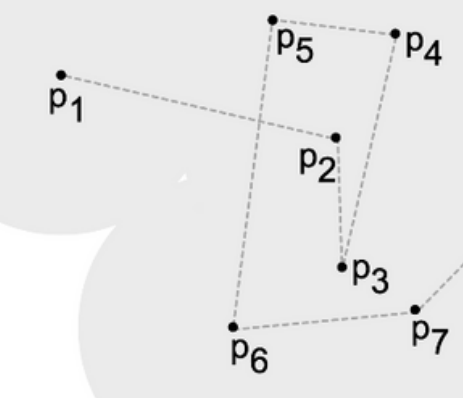

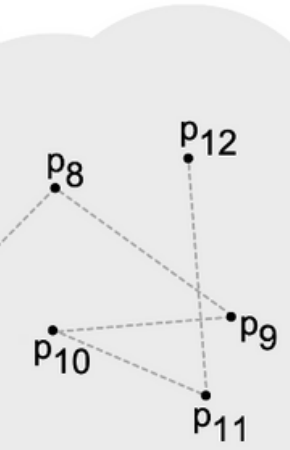

\section{Figure 2}

Schematic representation of First-Passage Time (FPT) measurement of Magellanic Woodpeckers moving at the site level (A) and home range level (B), as based on a trajectory with 12 relocations (pi). In $A$, the segment of the trajectory (in purple) represents the FPTB1 and in orange the FPTF2 of the circle with radius $r$ with center at $\mathrm{p} 2$. 


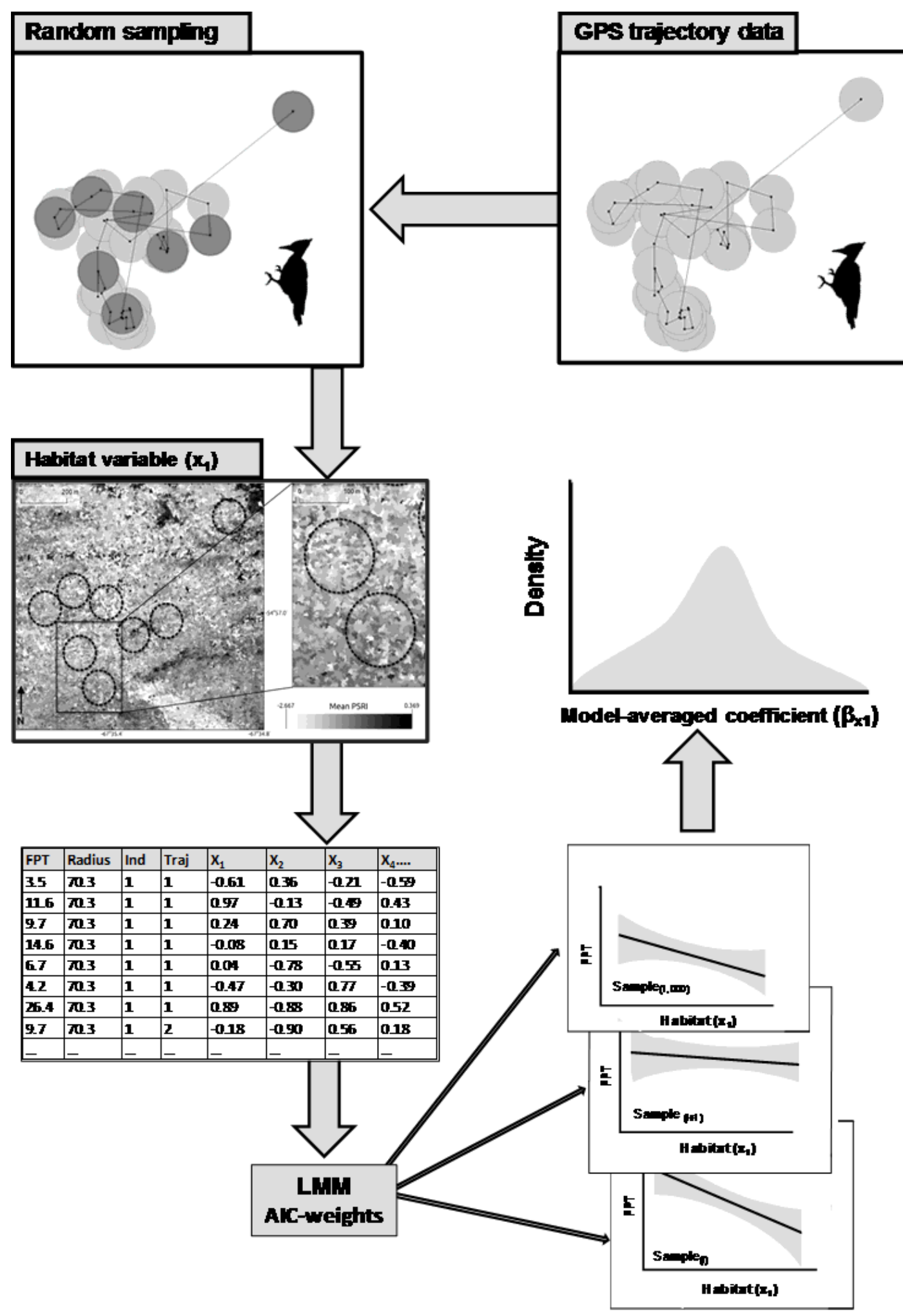

Figure 3

The methodological framework used to test the effects of habitat variables upon First-Passage Time (FPT) of Magellanic Woodpeckers based on the distibution of model averaged coefficients estimated from spatially independent data. AIC model averaging is performed on candidate LMMs fitted to a randomly sampled dataset. Habitat variables and FPT are estimated from random samples of nonoverlapping consecutive FPT circles along the trajectories of individual woodpeckers. 


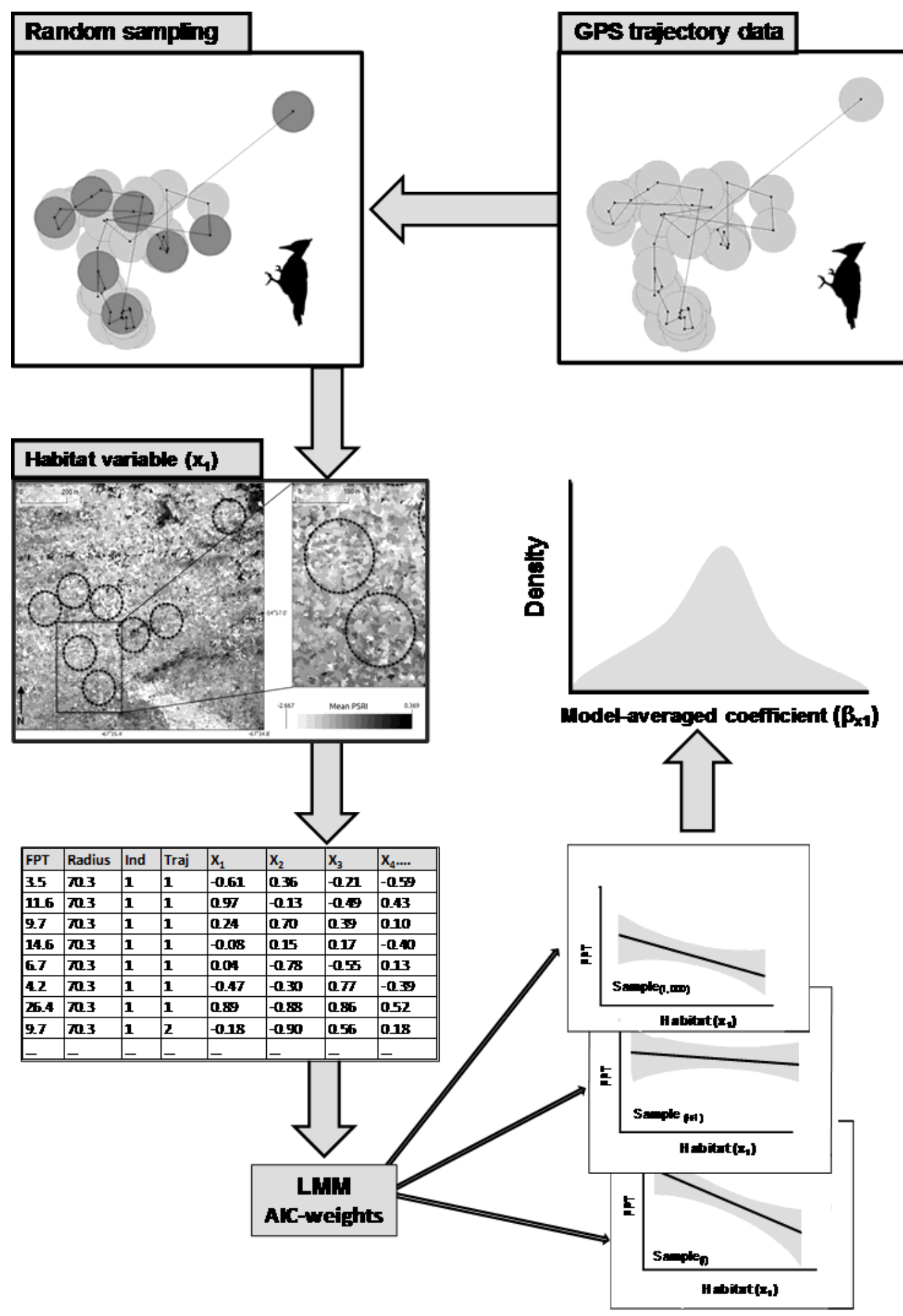

Figure 3

The methodological framework used to test the effects of habitat variables upon First-Passage Time (FPT) of Magellanic Woodpeckers based on the distibution of model averaged coefficients estimated from spatially independent data. AIC model averaging is performed on candidate LMMs fitted to a randomly sampled dataset. Habitat variables and FPT are estimated from random samples of nonoverlapping consecutive FPT circles along the trajectories of individual woodpeckers. 

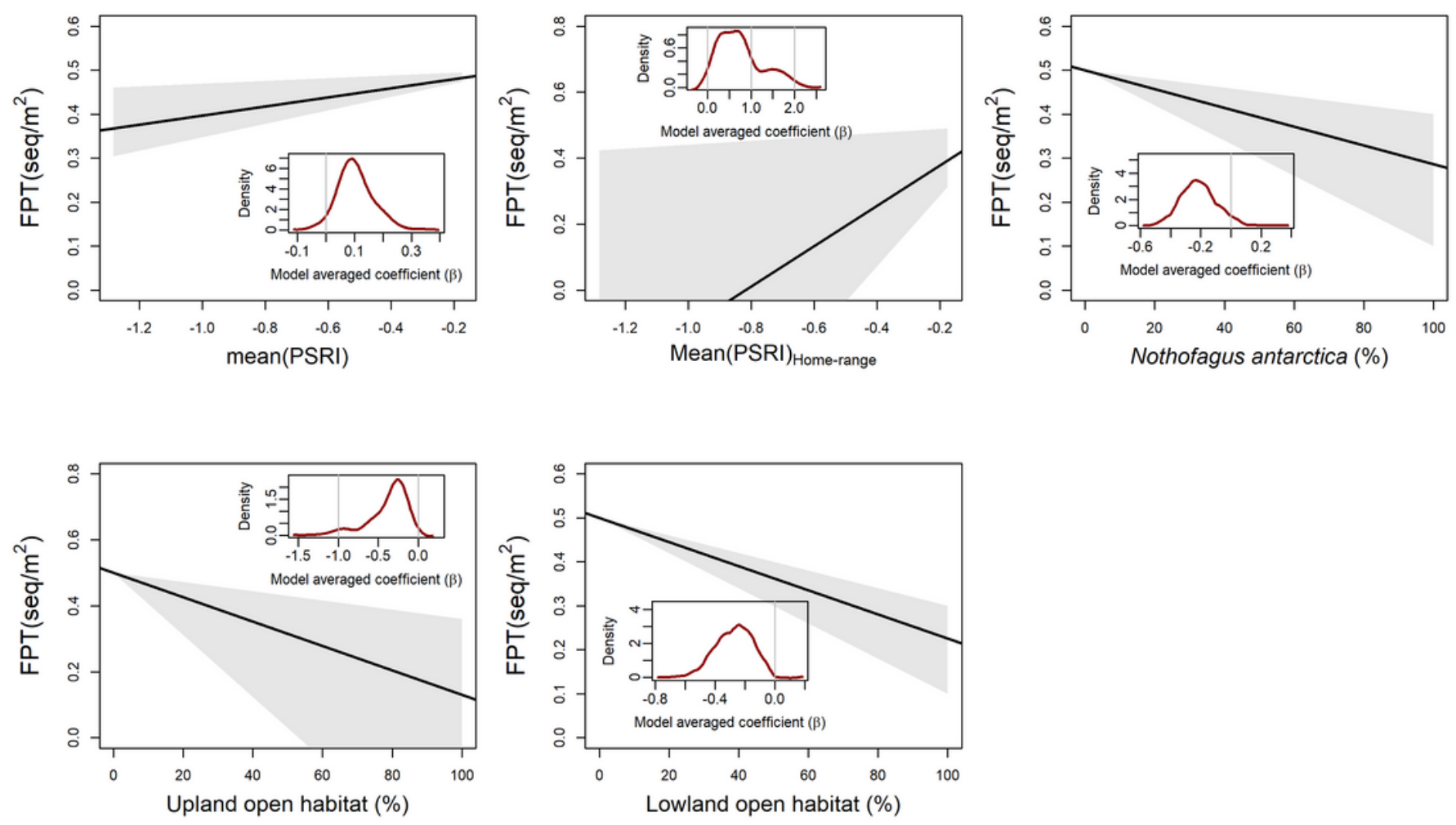

\section{Figure 4}

Relationships between habitat variables (Table 1) and First-Passage Time (FPT) values of Magellanic Woodpeckers predicted from the distribution of model-averaged coefficients shown in the inserted density histograms. Grey areas are confidence intervals of the prediction. 

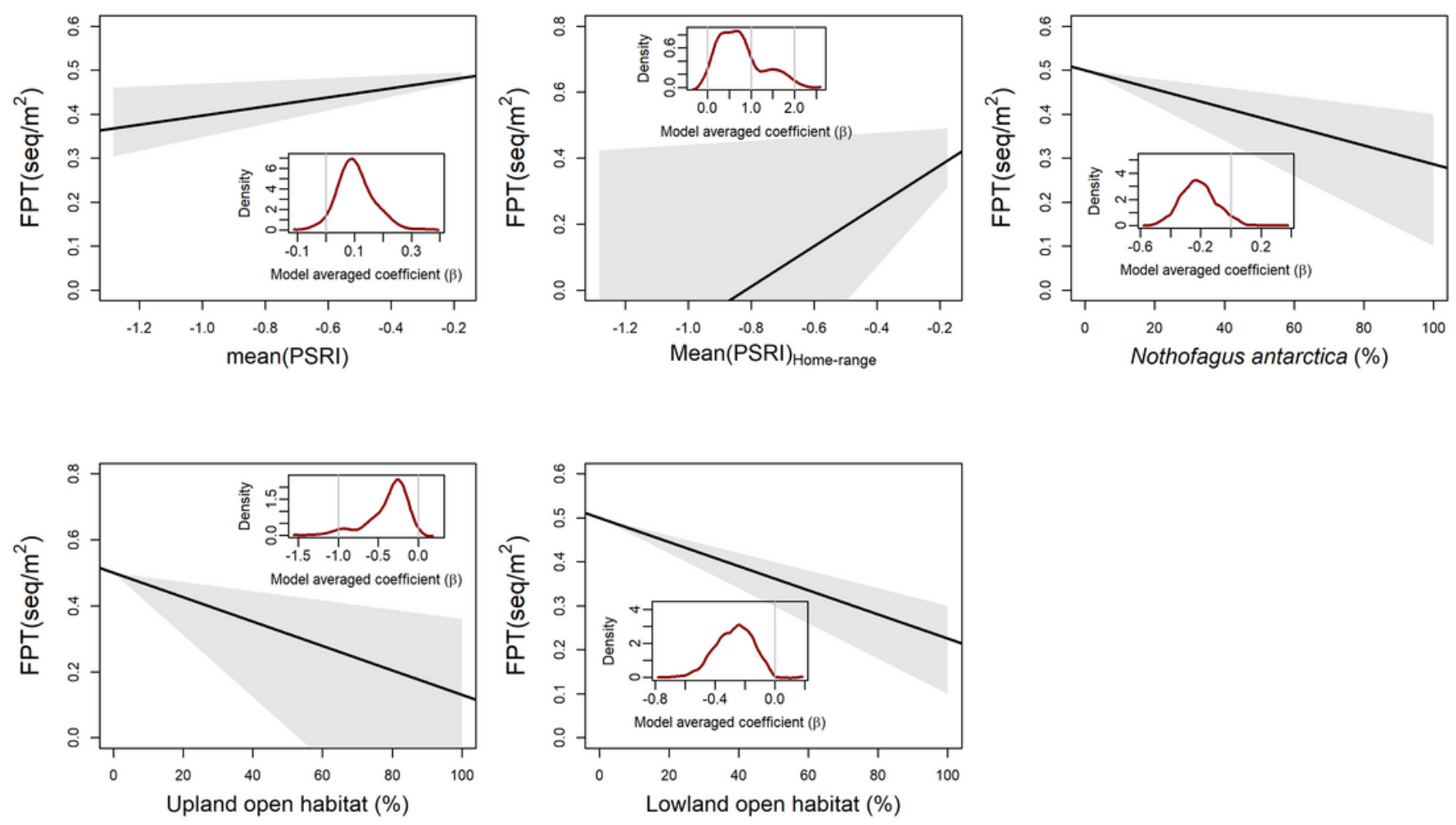

\section{Figure 4}

Relationships between habitat variables (Table 1) and First-Passage Time (FPT) values of Magellanic Woodpeckers predicted from the distribution of model-averaged coefficients shown in the inserted density histograms. Grey areas are confidence intervals of the prediction.

\section{Supplementary Files}

This is a list of supplementary files associated with this preprint. Click to download.

- SupplementaryMaterials.docx

- SupplementaryMaterials.docx 